\title{
Effects of Variable Viscosity and Thermal Conductivity on MHD Free Convective Flow Past an Inclined Surface with Viscous and Joule Dissipation
}

\author{
G.C. Hazarika \\ Department of Mathematics, \\ Dibrugarh University, Dibrugarh, Assam, India
}

\author{
Kabita Phukon \\ Department of Mathematics, \\ Gargaon College, Sivasagar, Assam, India
}

\begin{abstract}
A numerical investigation has been made to study the effects of variable viscosity and thermal conductivity on the steady twodimensional MHD free convection and mass transfer flow past an inclined semi-infinite surface in the presence of heat generation along with viscous and Joule dissipation. The partial differential equations governing the flow, temperature and concentration field of the problem are reduced to ordinary differential equations by using similarity transformations. The momentum, energy and concentration equations are solved numerically using shooting method along with fourth order Runge-kutta iteration scheme. The effects of various parameters viz. viscosity, thermal conductivity and mass transfer parameters on velocity, temperature and concentration field are presented graphically.
\end{abstract}

Finally, the numerical values of skin-friction co-efficient, Nusselt number and sheerwood number are also calculated.

\section{Keywords}

Variable viscosity, Thermal conductivity, Dissipation and Mass transfer.

\section{INTRODUCTION}

The problem of free convection and mass transfer flow of an electrically conducting fluid past an inclined heated surface under the influence of a magnetic field has attracted interest in view of its application in geophysics, astrophysics and many engineering problems, such as cooling of nuclear reactors, the boundary layer control in aerodynamics and cooling towers.

Viscous dissipation changes the temperature distributions by playing a role like an energy source which leads to affect heat transfer rates. The merit of the effect of viscous dissipation depends on whether the plate is being cooled or heated. Apart from the viscous dissipation in MHD flows, the Joule dissipation also acts as a volumetric heat source.

In light of these applications, Umemura and Law [1] developed a generalized formulation for the natural convection boundary layer flow over a flat plate with arbitrary inclination. They found that the flow characteristics depend not only on the extent of inclination but also on the distance from the leading edge. Hossain et al.[2] studied the free convection flow from an isothermal plate inclined at a small angle to the horizontal. Anghel et al.[3] presented a numerical solution of free convection flow past an inclined surface. Chen [4] performed an analysis to study the natural convection flow over a permeable inclined surface with variable wall temperature and concentration. He observed that increasing the angle of inclination decreases the effect of boundary force. Hazarika and Sarma [5] have studied the effects of variable viscosity and thermal conductivity on heat and mass transfer flow along a vertical plate in the presence of a magnetic field. Chen [6] has examined the effect of combined heat and mass transfer on MHD free convection from a vertical surface with ohmic heating and viscous dissipation. The flow and heat transfer due to a stretching porous surface in presence of transverse magnetic field including heat due to viscous dissipation is analyzed by Tak and Lodha [7] in 2005. Alam et al [8] has theoretically investigated the effects of viscous dissipation on natural convection flow over a sphere in the presence of magnetic field and heat generation for an electrically conducting fluid. Also Alam et. al [9] studied the free convective heat and mass transfer flow past an inclined surface with heat generation.

The physical properties of fluids such as viscosities and thermal conductivities were assumed to be constant in most of the studies. It is known that these physical properties change significantly with temperature and when the effects of variable viscosity and thermal conductivity are taken into account, the flow characteristics are significantly changed compared to the constant property case.

Here, the problems under consideration, the viscosity and thermal conductivity have been assumed to be inverse linear functions of temperature.

In the present paper, an investigation is made to study the effect of variable viscosity and thermal conductivity on MHD free convection and mass transfer flow past an inclined surface with viscous and Joule dissipation based on the work of M.S.Alam, M.M.Rahman and M.A.Sattar [9].

\section{MATHEMATICAL FORMULATION OF THE PROBLEM}

We consider a steady two-dimensional hydromagnetic flow of a viscous incompressible, electrically conducting fluid past a semi-infinite inclined plate with an acute angle $\boldsymbol{\alpha}$ to the vertical. The flow is assumed to be in the $\mathrm{x}$-direction, which is taken along the semi-infinite inclined plate and $\mathrm{y}$-axis normal to it. A magnetic field of uniform strength $B_{0}$ is introduced normal to the direction of the flow. In this analysis, we assume that the magnetic Reynolds number is much less than unity so that the induced magnetic field is neglected in comparison to the applied magnetic field. The surface is maintained at a constant temperature $T_{w}$, which is higher than the constant temperature $\mathrm{T}_{\infty}$ of the surrounding fluid and the concentration $\mathrm{C}_{\mathrm{w}}$ is greater than the constant concentration $\mathrm{C}_{\infty}$.

The density is considered a linear function of temperature and species concentration so that the usual Boussinesq's approximation is taken as-

$$
\rho=\rho_{0}\left[1-\left\{\beta\left(T-T_{\infty}\right)+\beta^{*}\left(c-c_{\infty}\right)\right\}\right]
$$

Fluid viscosity and thermal conductivity are assumed to vary with temperature. 
With the above assumptions, the equations of continuity, momentum, energy and the concentrations are-

\section{Continuity equation:}

$\frac{\partial u}{\partial x}+\frac{\partial v}{\partial y}=0$

\section{Momentum equation:}

$\rho\left(u \frac{\partial u}{\partial x}+v \frac{\partial u}{\partial y}\right)=\frac{\partial}{\partial y}\left(\mu \frac{\partial u}{\partial y}\right)+\rho g \beta\left(T-T_{\infty}\right) \cos \alpha+$ $\rho g \beta^{*}\left(C-C_{\infty}\right) \cos \alpha-\sigma B_{0}^{2} u$

\section{Energy equation:}

$u \frac{\partial T}{\partial x}+v \frac{\partial T}{\partial y}=\frac{1}{\rho c_{p}} \frac{\partial}{\partial y}\left(K \frac{\partial T}{\partial y}\right)+\frac{Q_{0}}{\rho c_{p}}\left(T-T_{\infty}\right)+\frac{1}{\rho c_{p}} \mu\left(\frac{\partial u}{\partial y}\right)^{2}+$ $\frac{1}{\rho c_{p}} \sigma\left(u B_{0}\right)^{2}$

\section{Concentration equation:}

$$
u \frac{\partial C}{\partial x}+v \frac{\partial C}{\partial y}=\frac{\partial}{\partial y}\left(D \frac{\partial C}{\partial y}\right)
$$

The boundary conditions relevant to the problem are:

$$
\begin{array}{r}
u=0, v=0, T=T_{w}, C=C_{w} \text { at } y=0 \\
u=0, T=T_{\infty}, C=C_{\infty} \text { at } y \rightarrow \infty
\end{array}
$$

where $u, v$ are velocity components along $x$-axis and $y$-axis, g is the acceleration due to gravity, $T$ is the temperature, $T_{w}$ is the wall temperature, $T_{\infty}$ is the temperature of the uniform flow, $K$ is the thermal conductivity of fluid, $D$ is the mass diffusivity, $C$ is the concentration of species, $C_{\infty}$ is the concentration of species for uniform flow, $B_{0}$ is the applied magnetic field, $C p$ is the specific heat at constant pressure, $Q_{0}$ is the heat generation constant, $\boldsymbol{\rho}$ is the density, $\boldsymbol{v}$ is the kinematic viscosity, $\boldsymbol{\beta}$ is the volumetric co-efficient of thermal expansion with concentration and the other symbols have their usual meaning.

Let the following non-dimensional variables is introduced as:

$\eta=y \sqrt{\frac{U_{\infty}}{v_{\infty} x}}, u=U_{\infty} f^{\prime}(\eta), v=\frac{1}{2} \sqrt{\frac{U_{\infty} v_{\infty}}{x}}\left(\eta f^{\prime}-f\right), \theta(\eta)=$ $\frac{T-T_{\infty}}{T_{w}-T_{\infty}}, \varphi(\eta)=\frac{C-C_{\infty}}{C_{w}-C_{\infty}}$

In the light of Lai and Kulaki [10], viscosity of the fluid is assumed as

$\frac{1}{\mu}=\frac{1}{\mu_{\infty}}\left[1+\gamma\left(T-T_{\infty}\right)\right]$ or $\frac{1}{\mu}=a\left(T-T_{r}\right)$

where

$$
a=\frac{\gamma}{\mu_{\infty}} \quad \text { and } \quad T_{r}=T_{\infty}-\frac{1}{\gamma}
$$

where $\mu$ is the fluid viscosity, $\mu_{\infty}$ is the viscosity at free stream, $T$ is the temperature, $T_{\infty}$ is the temperature at free stream, $\gamma$ is the constant based on the thermal property of the fluid.

Further following Khound and Hazarika [11], let the thermal conductivity be-

$$
\frac{1}{k}=\frac{1}{k_{\infty}}\left[1+\xi\left(T-T_{\infty}\right)\right] \text { or } \frac{1}{k}=b\left(T-T_{c}\right)
$$

where,

$$
b=\frac{\xi}{k_{\infty}} \quad \text { and } \quad T_{c}=T_{\infty}-\frac{1}{\xi}
$$

where $k$ and $T$ are the thermal conductivity and temperature of the fluid, $k_{\infty}$ and $T_{\infty}$ are the thermal conductivity and temperature at free stream, $\xi$ is a constant based on the thermal property of the fluid.

The non-dimensional form of viscosity and thermal conductivity parameters $\theta_{r}$ and $\theta_{c}$ can be written as

$$
\theta_{r}=\frac{T_{r}-T_{\infty}}{T_{w}-T_{\infty}}, \theta_{c}=\frac{T_{c}-T_{\infty}}{T_{w}-T_{\infty}}
$$

The above substitutions, equation (1) is identically satisfied and equations (2) to (4) reduced to

$f^{/ / /}-\frac{1}{2}\left(\frac{\theta-\theta_{r}}{\theta_{r}}\right) f f^{/ /}-\frac{1}{\left(\theta-\theta_{r}\right)} \theta^{/} f^{/ /}-\left(\frac{\theta-\theta_{r}}{\theta_{r}}\right) G_{r} \theta \cos \alpha-$ $\left(\frac{\theta-\theta_{r}}{\theta_{r}}\right) G_{m} \varphi \cos \alpha+\left(\frac{\theta-\theta_{r}}{\theta_{r}}\right) M f^{\prime}=0$

$\theta^{/ /}-\frac{1}{2}\left(\frac{\theta-\theta_{c}}{\theta_{c}}\right) P_{r} f \theta^{\prime}-\frac{1}{\left(\theta-\theta_{c}\right)} \theta^{/ 2}-\left(\frac{\theta-\theta_{c}}{\theta_{c}}\right) P_{r} Q \theta+$ $\left(\frac{\theta-\theta_{c}}{\theta_{c}}\right)\left(\frac{\theta_{r}}{\theta-\theta_{r}}\right) P_{r} E_{c} f^{/ / 2}-\left(\frac{\theta-\theta_{c}}{\theta_{c}}\right) P_{r} E_{c} M f^{/ 2}=0$

$\phi^{\prime /}-\frac{1}{2}\left(\frac{\theta-\theta_{r}}{\theta_{r}}\right) S_{c} f \phi^{\prime}-\frac{1}{\left(\theta-\theta_{r}\right)} \theta^{\prime} \phi^{\prime}=0$

where

$G_{r}=\frac{g \beta\left(T_{w}-T_{\infty}\right) x}{U_{\infty}^{2}} \quad$ is the local temperature Grashof number

$G_{m}=\frac{g \beta^{*}\left(C_{w}-C_{\infty}\right) x}{U_{\infty}^{2}}$ is the local mass Grashof number,

$M=\frac{\sigma B_{0}^{2}(x) x}{\rho U_{\infty}} \quad$ is the local magnetic field parameter,

$P_{r}=\frac{v_{\infty} \rho C_{p}}{K_{\infty}} \quad$ is the Prandtl number,

$Q=\frac{Q_{0} x}{\rho C_{p} U_{\infty}} \quad$ is the local Heat generation parameter and

$S_{c}=\frac{v_{\infty}}{D} \quad$ is the Schmidt number

The boundary conditions (5) transformed to

$f=0, f^{\prime}=0, \theta=1, \phi=1$ at $\left.\eta=o\right\}$

$f^{\prime}=0, \theta=0, \phi=0$ as $\eta \rightarrow \infty$

The local skin-friction co-efficient $\left(C_{f}\right)$, the local Nusselt number $(\mathrm{Nu})$ and the local Sheerwood number $(\mathrm{Sh})$ are the parameters of engineering interest which are given respectively as below-

\section{Co-efficient of skin-friction:}

$$
\begin{gathered}
\left.C_{f}=\frac{2 \tau_{w}}{\rho U_{\infty}^{2}} \text { where } \tau_{w}=\mu \frac{\partial u}{\partial y}\right)_{y=0} \text { is the Shearing Stress } \\
=>C_{f}=-\frac{2 \theta_{r}}{\left(1-\theta_{r}\right)} R_{e}^{-\frac{1}{2}} f^{/ /}(0)
\end{gathered}
$$

\section{Nusselt number:}

$$
\begin{gathered}
\left.N_{u}=\frac{x q_{w}}{k_{\infty}\left(T_{w}-T_{\infty}\right)} \quad \text { where } q_{w}=-k \frac{\partial T}{\partial y}\right)_{y=0} \\
=>N_{u}=\frac{\theta_{c}}{\left(1-\theta_{c}\right)} R_{e}^{\frac{1}{2}} \theta^{\prime}(0)
\end{gathered}
$$




\section{Sheerwood number:}

$$
\begin{gathered}
\left.S h=\frac{x h_{w}}{D\left(C_{w}-C_{\infty}\right)} \text {, where } h_{w}=-D \frac{\partial c}{\partial y}\right)_{y=0} \\
S h=\frac{\theta_{r}}{1-\theta_{r}} R_{e}^{\frac{1}{2}} \varphi^{\prime}(0)
\end{gathered}
$$

\section{RESULTS AND DISCUSSION}

The system of differential equations (7)-(9) governed by the boundary conditions (10) are solved numerically using RungeKutta fourth order method in conjunction with shooting technique.

The results are presented in graphs from fig-1 to fig-17 for velocity, temperature and concentration profile.

Table-1 to table- 4 gives the values of Co-efficient of skin friction $\left(C_{f}\right)$, Nusselt number $\left(N_{u}\right)$ and Sheerwood number $(S h)$, for various values of the flow governing parameters as indicated.

Velocity profile for various combination of parameters $M=.1$, $P_{r}=.7, \theta_{c}=-12, \theta_{r}=-12, Q=.25, G_{r}=1, G_{m}=1$, $S_{c}=.22, \alpha=30, E_{c}=.01$ are illustrated in fig-1 to fig- 6 . From these figures, it is observed that the velocity decreases with the increase of viscosity parameter $\left(\theta_{r}\right)$, thermal conductivity parameter $\left(\theta_{c}\right)$, magnetic parameter $(M)$, angle of inclination $(\alpha)$ and Schmidt number $\left(S_{c}\right)$. On the other hand velocity increases with the increase of Eckert number $\left(E_{c}\right)$.

Temperature profiles are illustrated from fig-7 to fig-12. From these figures it is seen that temperature decreases with the increase of viscosity parameter $\left(\theta_{r}\right)$ and thermal conductivity parameter $\left(\theta_{c}\right)$, but on the other hand, temperature increases with the increase of magnetic parameter $(M)$, angle of inclination $(\alpha)$, Eckert number $\left(E_{c}\right)$ and Schmidt number $\left(S_{c}\right)$.

Concentration profile for various values of $\theta_{r}, M, \alpha, E_{c}$ and $S_{c}$ are shown in fig-13 to fig-17. From these figures, it can be clearly observed that concentration decreases with the increase of viscosity parameter $\left(\theta_{r}\right)$, Eckert number $\left(E_{c}\right)$ and Schmidt number $\left(S_{c}\right)$ but it is increases with the increase of magnetic parameter $(M)$ and angle of inclination $(\alpha)$.

From Table- 1 and Table-2, it is observed that with the increase of $\theta_{r}$ (viscosity parameter), co-efficient of skin friction $\left(C_{f}\right)$ and rate of mass transfer $(S h)$ decreases but rate of heat transfer $\left(N_{u}\right)$ increases.

From Table- $2 \& 4$, it is seen that with the increase of $\theta_{c}$ (thermal conductivity parameter), $C_{f}$ and $N_{u}$ decrease but $S h$ increases.

From Table- $1 \& 2$, it is observed that for the increasing values of $M, C_{f}, N_{u}$ and $S h$ decreases.

Also from Table-3 \& 4, it is observed that for the increasing values of $S_{c}, C_{f}$ and $N_{u}$ decreases and $S h$ increases.

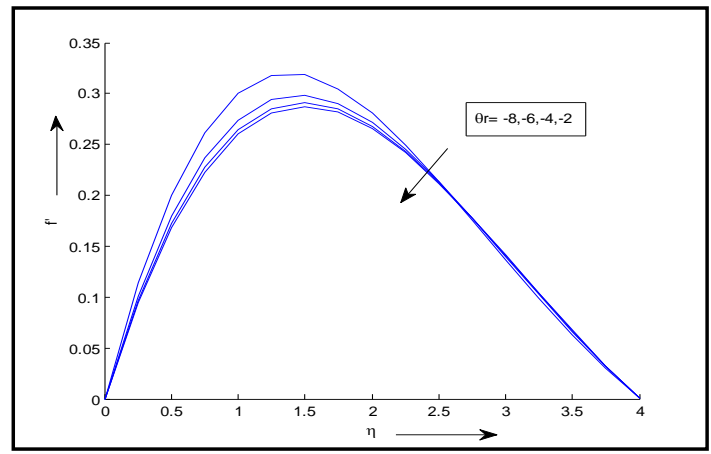

Fig- 1.Variation of velocity with $\theta_{r}$

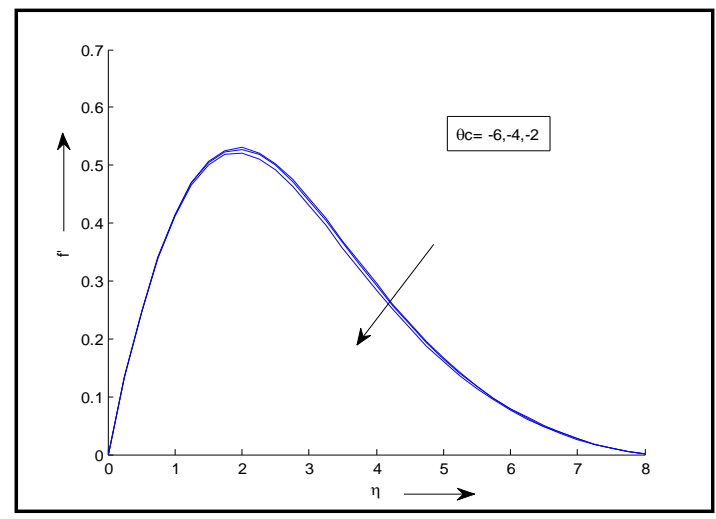

Fig- 2. Variation of velocity with $\theta_{c}$

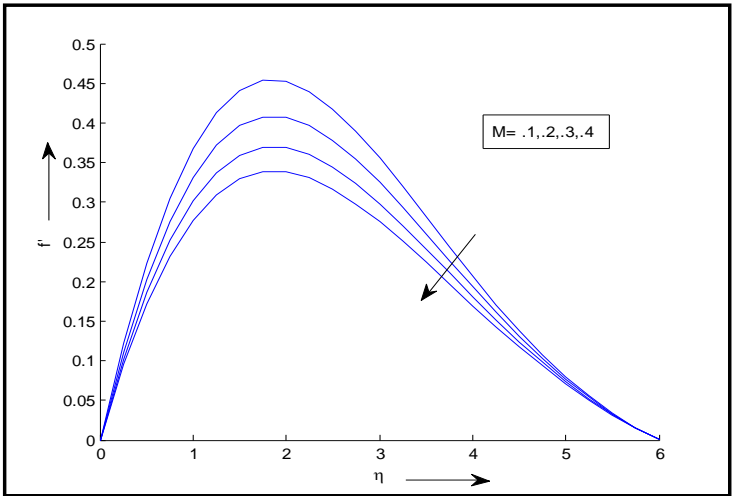

Fig- 3.Variation of velocity with $M$

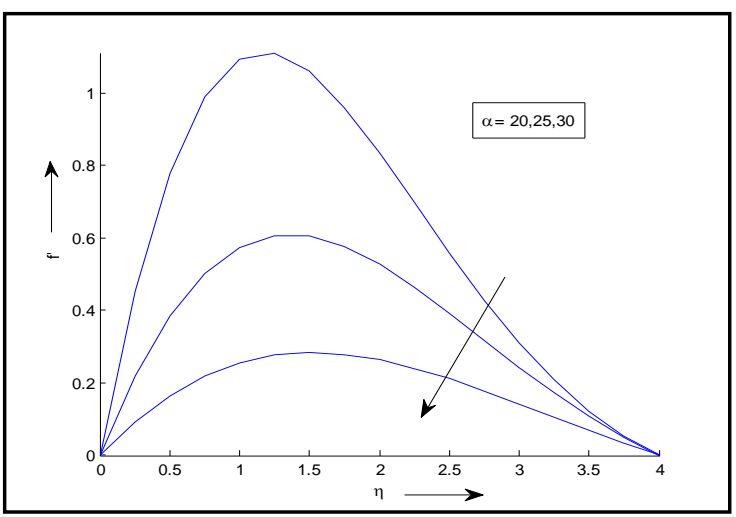

Fig- 4.Variation of velocity with $\alpha$ 


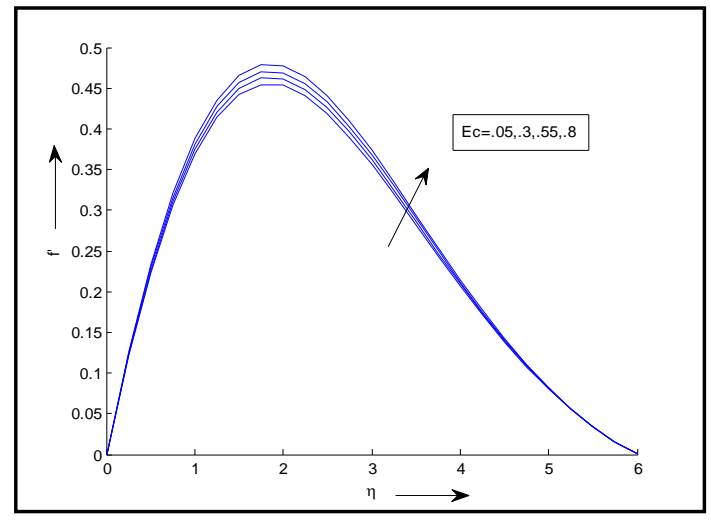

Fig- 5:-Variation of velocity with $E_{c}$

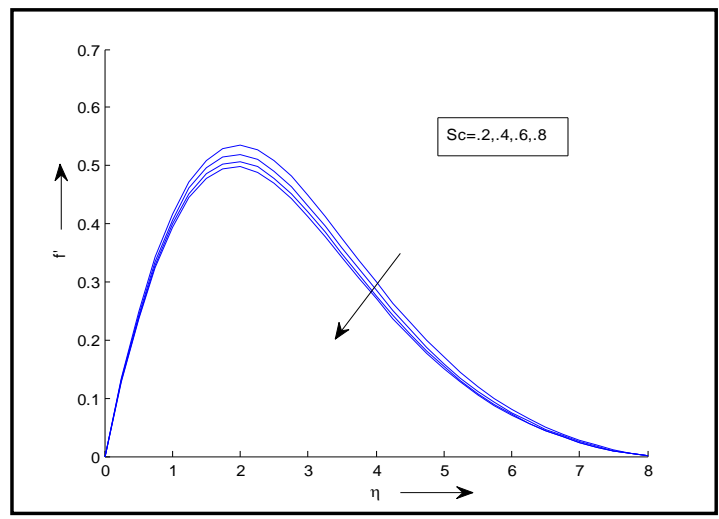

Fig- 6:-Variation of velocity with $S_{c}$

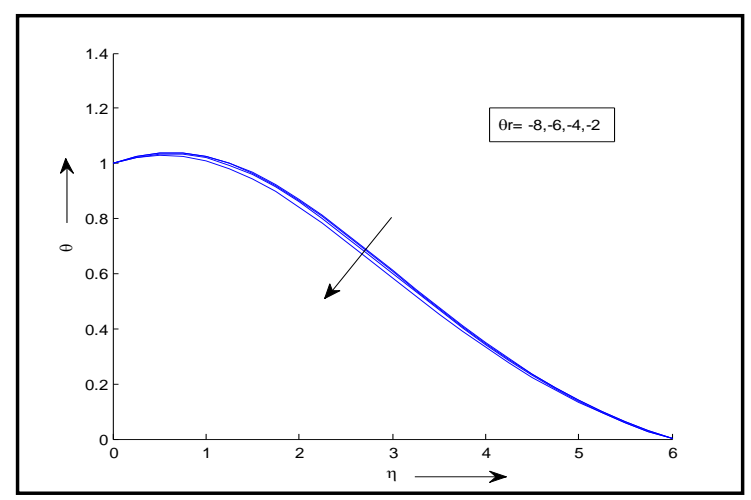

Fig- 7:-Variation of temperature with $\theta_{r}$

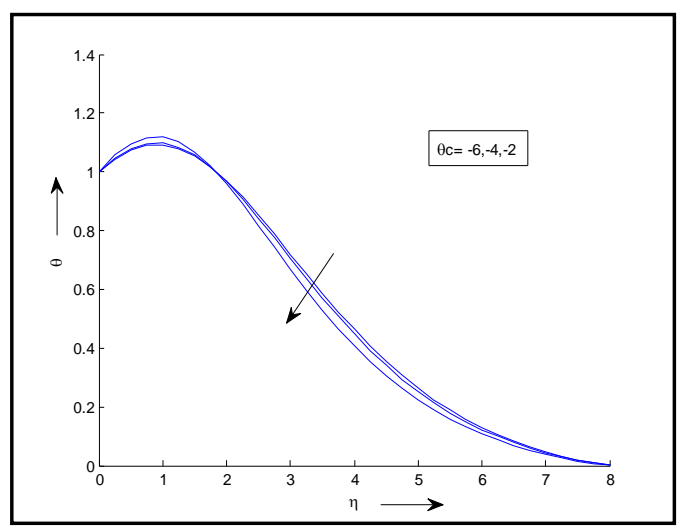

Fig- 8:-Variation of temperature with $\theta_{c}$

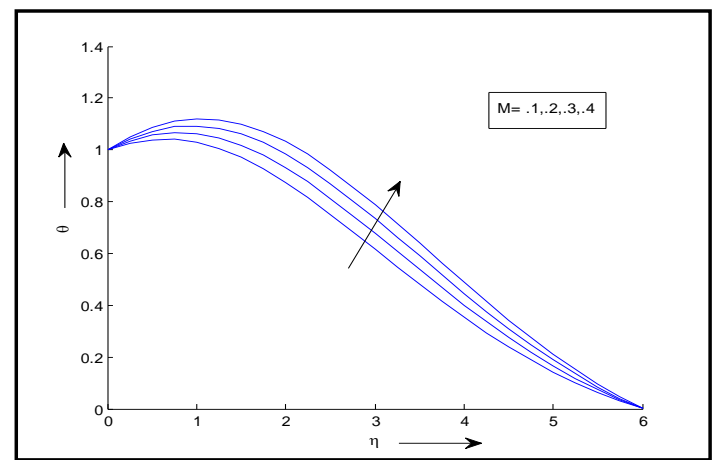

Fig- 9:-Variation of temperature with $M$

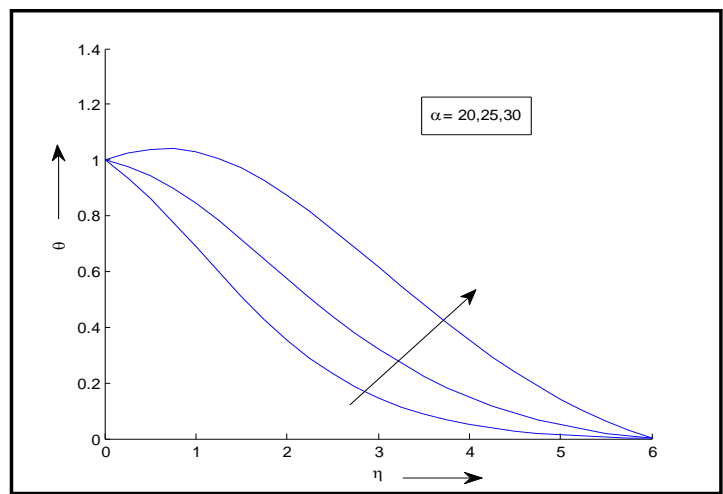

Fig- 10:-Variation of temperature with $\alpha$

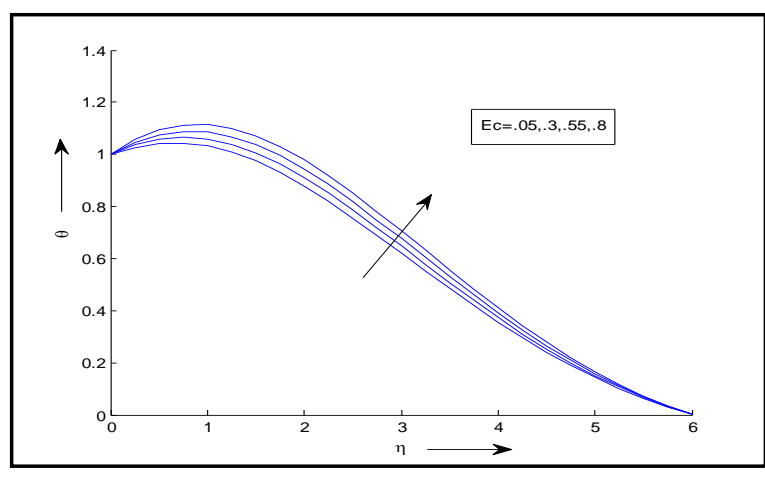

Fig- 11:Variation of temperature with $E_{c}$

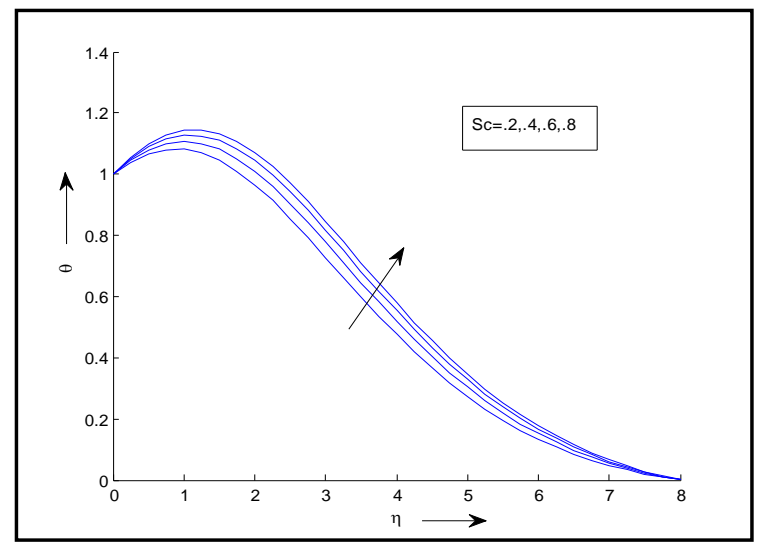

Fig- 12:Variation of temperature with $S_{c}$ 


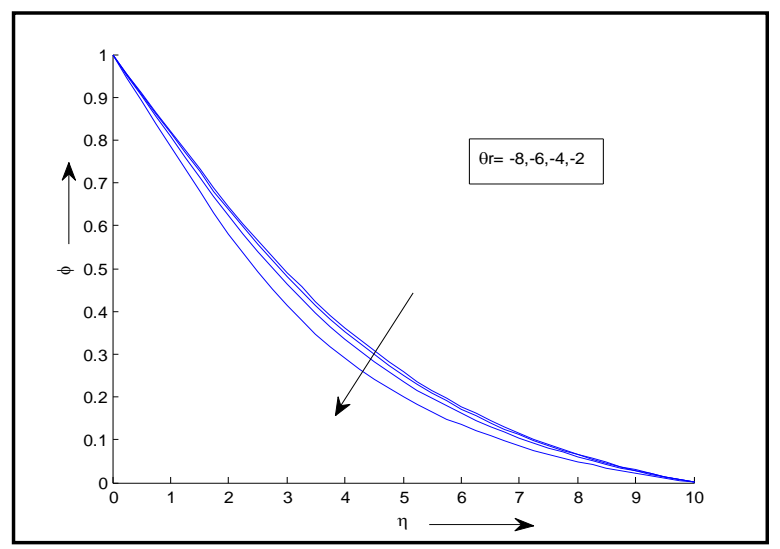

Fig- 13: Variation of concentration with $\theta_{r}$

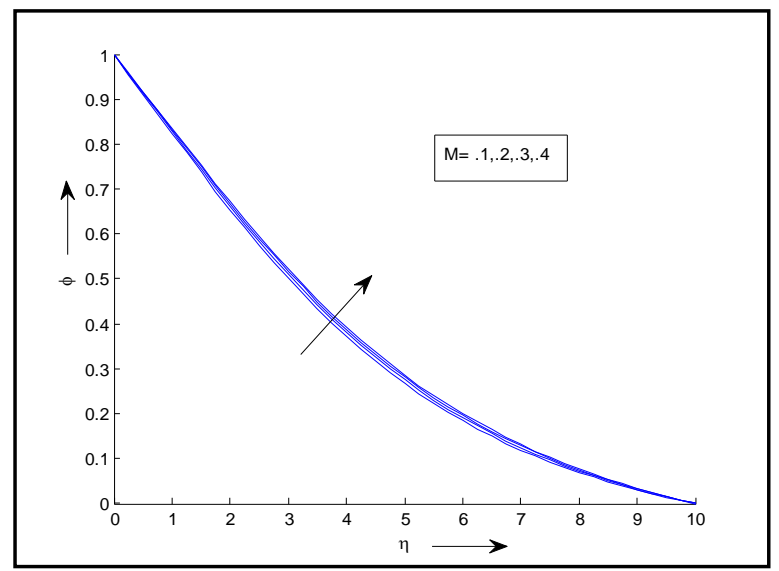

Fig- 14:Variation of concentration with $M$

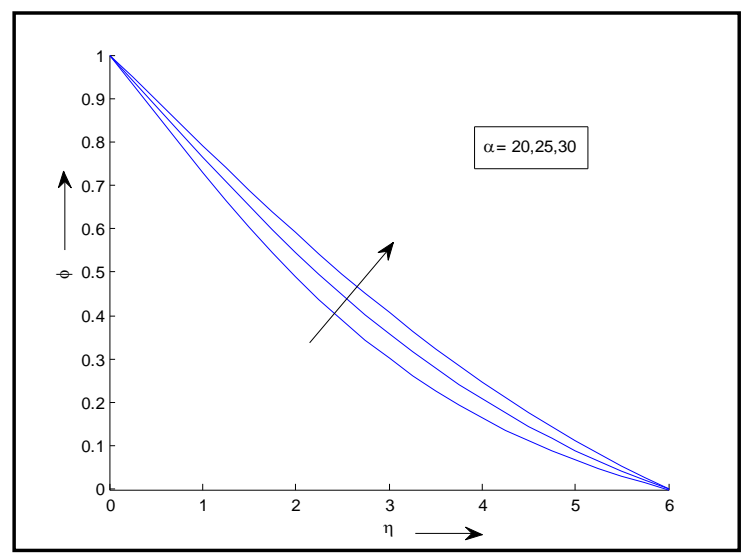

Fig- 15:Variation of concentration with $\alpha$

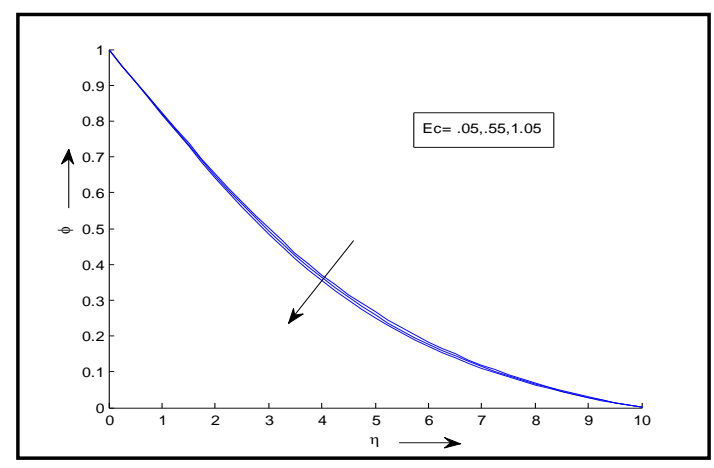

Fig- 16: Variation of concentration with $E_{c}$

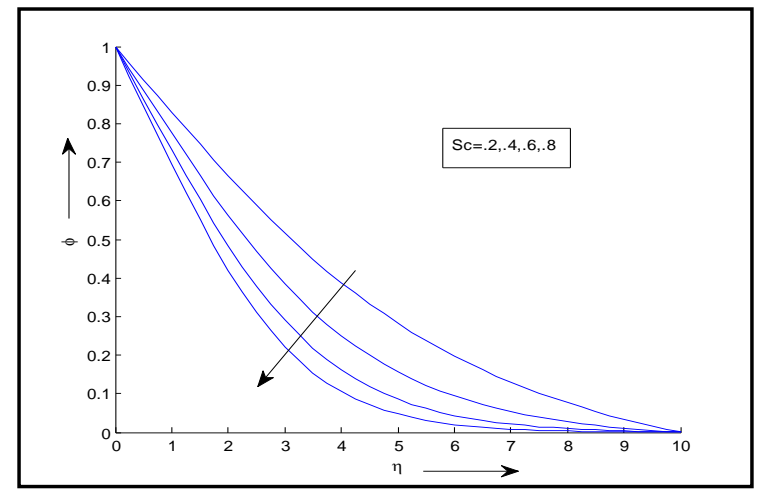

Fig- 17: Variation of concentration with $S_{c}$

Table 1

\begin{tabular}{|c|l|l|l|l|l|l|l|}
\hline \multicolumn{2}{|c}{$M$} & \multicolumn{1}{c}{$\theta_{r} f^{\prime \prime}(0)$} & \multicolumn{1}{c}{$\theta^{\prime}(0)$} & \multicolumn{1}{c}{$\varnothing_{f}^{\prime}(0)$} & \multicolumn{1}{c|}{$S_{u}$} \\
\hline \multirow{5}{*}{0.1} & -8 & 0.419965 & -0.02504 & -0.27751 & 2.360969 & 0.007199 & 0.078006 \\
\cline { 2 - 8 } & -6 & 0.430789 & -0.02633 & -0.28193 & 2.335325 & 0.007568 & 0.076417 \\
\cline { 2 - 8 } & -4 & 0.452051 & -0.02879 & -0.29036 & 2.287218 & 0.008276 & 0.073455 \\
\cline { 2 - 8 } & -2 & 0.51313 & -0.03542 & -0.31295 & 2.163547 & 0.010182 & 0.065976 \\
\hline \multirow{3}{*}{0.2} & -8 & 0.390274 & -0.01705 & -0.27587 & 2.194054 & 0.004902 & 0.077545 \\
\cline { 2 - 8 } & -6 & 0.39999 & -0.01814 & -0.28014 & 2.168364 & 0.005216 & 0.075931 \\
\cline { 2 - 8 } & -4 & 0.41905 & -0.02024 & -0.28825 & 2.120243 & 0.005818 & 0.072923 \\
\hline \multirow{2}{*}{0.3} & -2 & 0.47363 & -0.02586 & -0.30988 & 1.997001 & 0.007434 & 0.065328 \\
\hline
\end{tabular}




\begin{tabular}{|l|l|l|l|l|l|l|l|}
\hline & -6 & 0.374417 & -0.0113 & -0.27864 & 2.02973 & 0.003249 & 0.075527 \\
\cline { 2 - 7 } & -4 & 0.391729 & -0.0131 & -0.28651 & 1.982012 & 0.003766 & 0.072481 \\
\cline { 2 - 8 } & -2 & 0.441176 & -0.01791 & -0.30733 & 1.860162 & 0.00515 & 0.064792 \\
\hline \multirow{3}{*}{0.4} & -8 & 0.344731 & -0.0047 & -0.27335 & 1.938016 & 0.001351 & 0.076837 \\
\cline { 2 - 8 } & -6 & 0.352853 & -0.00552 & -0.27739 & 1.912832 & 0.001586 & 0.075186 \\
\cline { 2 - 8 } & -4 & 0.368755 & -0.00707 & -0.28503 & 1.865771 & 0.002034 & 0.072108 \\
\cline { 2 - 8 } & -2 & 0.414075 & -0.01124 & -0.3052 & 1.745895 & 0.00323 & 0.064341 \\
\hline
\end{tabular}

Table 2

\begin{tabular}{|c|c|c|c|c|c|c|c|}
\hline$M$ & $\theta_{c}$ & $f^{\prime \prime}(0)$ & $\theta^{\prime}(0)$ & $\emptyset^{\prime}(0)$ & $C_{f}$ & $N_{u}$ & $S_{h}$ \\
\hline \multirow{4}{*}{0.1} & -8 & 0.41328 & -0.02202 & -0.2748 & 2.376191 & 0.006189 & 0.079 \\
\hline & -6 & 0.413091 & -0.0182 & -0.27482 & 2.375104 & 0.004933 & 0.079004 \\
\hline & -4 & 0.41278 & -0.01022 & -0.27484 & 2.373319 & 0.002586 & 0.079012 \\
\hline & -2 & 0.412312 & 0.016194 & -0.2749 & 2.370626 & -0.00341 & 0.079029 \\
\hline \multirow{4}{*}{0.2} & -8 & 0.384313 & -0.01392 & -0.27325 & 2.209643 & 0.003914 & 0.078554 \\
\hline & -6 & 0.384215 & -0.00973 & -0.27327 & 2.209083 & 0.002638 & 0.078559 \\
\hline & -4 & 0.384082 & -0.00099 & -0.27329 & 2.208318 & 0.00025 & 0.078566 \\
\hline & -2 & 0.38411 & 0.027884 & -0.27335 & 2.208479 & -0.00588 & 0.078582 \\
\hline \multirow{4}{*}{0.3} & -8 & 0.360194 & -0.00714 & -0.27196 & 2.070968 & 0.002007 & 0.078183 \\
\hline & -6 & 0.360165 & -0.00263 & -0.27198 & 2.070803 & 0.000712 & 0.078187 \\
\hline & -4 & 0.360165 & 0.006779 & -0.272 & 2.070804 & -0.00172 & 0.078194 \\
\hline & -2 & 0.360565 & 0.037791 & -0.27205 & 2.073106 & -0.00797 & 0.078209 \\
\hline \multirow{4}{*}{0.4} & -8 & 0.339804 & -0.00139 & -0.27087 & 1.953737 & 0.00039 & 0.07787 \\
\hline & -6 & 0.339828 & 0.003402 & -0.27088 & 1.953871 & -0.00092 & 0.077874 \\
\hline & -4 & 0.339928 & 0.013385 & -0.27091 & 1.954449 & -0.00339 & 0.07788 \\
\hline & -2 & 0.340608 & 0.046276 & -0.27095 & 1.958359 & -0.00976 & 0.077892 \\
\hline
\end{tabular}

Table 3

\begin{tabular}{|c|c|c|c|c|c|c|c|}
\hline$S_{c}$ & $\theta_{r}$ & $f^{\prime \prime}(0)$ & $\theta^{\prime}(0)$ & $\emptyset^{\prime}(0)$ & $C_{f}$ & $N_{u}$ & $S_{h}$ \\
\hline \multirow{4}{*}{0.2} & -8 & 0.420285 & -0.02514 & -0.27615 & 2.362768 & 0.007227 & 0.077622 \\
\hline & -6 & 0.431126 & -0.02643 & -0.28051 & 2.337154 & 0.007598 & 0.076032 \\
\hline & -4 & 0.452424 & -0.0289 & -0.28882 & 2.289103 & 0.008308 & 0.073067 \\
\hline & -2 & 0.513615 & -0.03556 & -0.31108 & 2.165589 & 0.010221 & 0.065581 \\
\hline \multirow{4}{*}{0.4} & -8 & 0.417142 & -0.02417 & -0.28966 & 2.3451 & 0.006948 & 0.081421 \\
\hline & -6 & 0.427815 & -0.02542 & -0.29457 & 2.319207 & 0.007308 & 0.079843 \\
\hline & -4 & 0.448771 & -0.02781 & -0.30397 & 2.270619 & 0.007995 & 0.0769 \\
\hline & -2 & 0.508883 & -0.03423 & -0.32954 & 2.145639 & 0.00984 & 0.069472 \\
\hline \multirow{4}{*}{0.6} & -8 & 0.414127 & -0.02324 & -0.30285 & 2.328151 & 0.006682 & 0.085127 \\
\hline & -6 & 0.424644 & -0.02446 & -0.30827 & 2.302014 & 0.007031 & 0.083557 \\
\hline & -4 & 0.44528 & -0.02677 & -0.31872 & 2.252961 & 0.007697 & 0.080629 \\
\hline & -2 & 0.504398 & -0.03298 & -0.34741 & 2.12673 & 0.00948 & 0.073239 \\
\hline
\end{tabular}

Table 4

\begin{tabular}{|c|l|l|l|l|l|l|l|}
\hline \multicolumn{2}{|c}{$S_{c}$} & $\theta_{c}$ & \multicolumn{1}{c}{$f^{\prime \prime}(0)$} & \multicolumn{1}{c}{$\theta^{\prime}(0)$} & \multicolumn{1}{c}{$\emptyset^{\prime}(0)$} & $C_{f}$ & $S_{u}$ \\
\hline \multirow{4}{*}{0.2} & -8 & 0.413589 & -0.02212 & -0.27347 & 2.377969 & 0.006217 & 0.078617 \\
\cline { 2 - 8 } & -6 & 0.413399 & -0.0183 & -0.27349 & 2.376874 & 0.004961 & 0.078622 \\
\cline { 2 - 8 } & -4 & 0.413086 & -0.01033 & -0.27352 & 2.375077 & 0.002614 & 0.07863 \\
\hline
\end{tabular}




\begin{tabular}{|l|l|l|l|l|l|l|l|}
\hline & -2 & 0.412611 & 0.016051 & -0.27358 & 2.372349 & -0.00338 & 0.078649 \\
\hline \multirow{4}{*}{0.4} & -8 & 0.410552 & -0.02115 & -0.28665 & 2.360511 & 0.005944 & 0.082406 \\
\cline { 2 - 8 } & -6 & 0.410373 & -0.01729 & -0.28665 & 2.35948 & 0.004686 & 0.082406 \\
\cline { 2 - 8 } & -4 & 0.410082 & -0.00923 & -0.28665 & 2.357806 & 0.002334 & 0.082406 \\
\cline { 2 - 8 } & -2 & 0.409668 & 0.017448 & -0.28665 & 2.355427 & -0.00368 & 0.082406 \\
\hline \multirow{3}{*}{0.6} & -8 & 0.407637 & -0.02022 & -0.29951 & 2.343749 & 0.005682 & 0.086104 \\
\cline { 2 - 8 } & -6 & 0.407468 & -0.01632 & -0.2995 & 2.342778 & 0.004423 & 0.0861 \\
\cline { 2 - 8 } & -4 & 0.407198 & -0.00817 & -0.29947 & 2.341221 & 0.002066 & 0.086092 \\
\cline { 2 - 8 } & -2 & 0.406841 & 0.018785 & -0.29942 & 2.33917 & -0.00396 & 0.086076 \\
\hline
\end{tabular}

\section{CONCLUSION}

From the above study, it is clear that the viscosity and thermal conductivity parameter along with the other parameters such as Magnetic parameter M, Schmidt number $S_{c}$, Eckert number $E_{c}$ etc have significant effects on velocity, temperature and concentration profile within the boundary layer.

Thus, it can be concluded that-

1. Viscosity, Thermal Conductivity and Magnetic field retard the fluid velocity.

2. Hartman number enhances the concentration and fluid temperature.

3. Mass transfer rate decreases for the increase of viscosity parameter whereas it increases with the increase of Hartmann number (M).

4. In the presence of viscous and Joule dissipation, the inclination angle $\alpha$, retards the fluid velocity.

5. Eckert number enhances the fluid velocity and temperature.

\section{REFERENCES}

[1] Umemura, A. and Law, C.K., 1990, "Natural Convection Boundary Layer flow over a Heated Plate with Arbitrary Inclination", J. Fluid Mech., Vol-219, pp. 571-584.

[2] Hossain, M.A., Pop, I. and Ahmed, M., 1996, "MHD Free Convection Flow from an Isothermal Plate Inclined at a Small Angle to the Horizontal", J. Theoretical and Appl. Fluid Mech., Vol-1, pp. 194-207.

[3] Anghel, M., Hossain, M.A., Zeb, S. and Pop, I., 2001, "Combined Heat and Mass Transfer by Free Convection Past an Inclined Flat Plate", Int. J. Appl. Mech. And Engng, Vol-2, pp. 473-497.

[4] Chen, C.H., 2004, "Heat and Mass Transfer in MHD Flow by Natural Convection from a Permeable Inclined
Surface with Variable Wall Temperature and Concentration", Acta Mechanica, Vol-172, pp. 219-235.

[5] Hazarika.,G.C. and Sarma.,U., 2011,"Effects of Variable Viscosity and Thermal Conductivity on Heat and Mass Transfer Flow along a Vertical Plate in the Presence of a Magnetic Field", Lat. Am .J. Phy. Educ., Vol-5,No-1, pp.100-106.

[6] Chen,C.H., 2004,"Combined heat and mass transfer in MHD free convection from a vertical surface with ohmic heating and viscous dissipation", Int. J. Eng. Sci., 42,pp. 699-713.

[7] Tak,S.S. and Lodha,A., 2005,"Flow and heat transfer due to a stretching porous surface in presence of transverse magnetic field", Acta Ciencia Indica, XXXI M93), pp. 657-663.

[8] Alam,M.M., Alim,M.A. and Choudhury,M.M.K., 2007,"Viscous dissipation effects on MHD natural convection flow over a sphere in the presence of heat generation", Nonlinear Anal. Model Control, 12(4), pp. $47-459$.

[9] Alam, M.S., Rahman, M.M. and Sattar, M.A., 2006 , "MHD free Convective Heat and Mass Transfer Flow Past an Inclined Surface with Heat Generation", Thammasat Int. J. Sc. Tech., Vol-11, No-4, pp-1-8.

[10] Lai, F.C. and Kulacki, F.A., 1991, "Coupled heat and mass transfer by natural convection from vertical surfaces in a porous medium”, Int. J. Heat Mass Transfer, Vol-34, pp-1189-94,.

[11] Khound, P.K. and Hazarika, G.C., 2000, "The effect of variable viscosity and thermal conductivity on liquid film on an unsteady stretching surface", Proc. of $46^{\text {th }}$ Annual Tech. Session, Ass. Sc. Soc., pp.47 - 56 . 